\title{
Step right up to the library! The Week of Welcome carnival at the University of Alabama Libraries
}

n collaboration with the Division of Student

Affairs, the University of Alabama (UA) Libraries created a carnival to welcome freshmen students during the first week of school. Each year, Student Affairs organizes a series of events across campus during the first few days of the fall semester known as Week of Welcome (wOW). Similar to "freshmen jam" at other campuses, WOW introduces freshmen to campus; it features lectures, orientations, parties, concerts, and other events at the Recreation Center, student union, stadium,

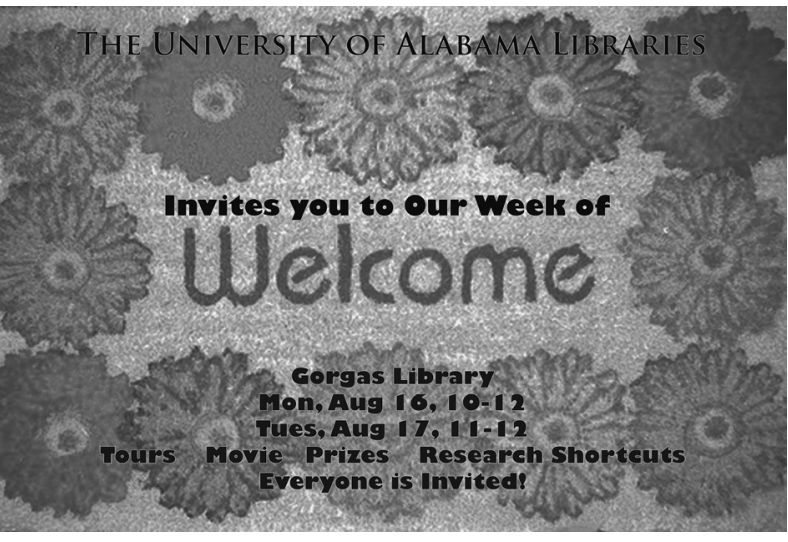

Figure 1. "Welcome mat" poster in the student union. we had to be able to accommodate a small or large number of students. Student Affairs advertised the WOW events through Web sites and the student newspaper, and therefore we could not know ahead of time how many people would come and when they might arrive. We could offer a simple open house as in the past; however, we wanted to provide more opportunities for promotion and instruction covering the specialized libraries' services, Gorgas Library's facilities, electronic resources, and good research habits. It seemed that a as well as various academic-related units. The UA Libraries, consisting of the Amelia Gayle Gorgas Library (the main library for freshmen) and several specialized libraries, have also participated in WOW in the past by offering an open house with refreshments and ad hoc tours. A recent ACRL e-learning course, "Libraries and Student Affairs: Collaborating to Support Holistic Student Development" by Lisa Janicke Hinchliffe and Melissa Wong, helped us rethink and enhance the format for 2010.

\section{Why a carnival?}

We offered a format this year that included a carnival of events. In making our plans carnival consisting of several activities would be able to accomplish these goals, and we planned accordingly.

\section{The carnival begins!}

We helped Student Affairs advertise the event in the student union with posters that had a "welcome mat" theme created by Reference Librarian Michael Pearce (Figure 1). As fresh-

Melissa Fortson is research and instructional services librarian, mbfortson@ua.edu, Josh Sahib is research and instructional services librarian, e-mail: jsahib@ ua.edu, and Brett Spencer, is freshman services librarian, e-mail: dbspence@ua.edu, at the University of AlabamaTuscaloosa

๑C 2011 Melissa Fortson, Josh Sahib, Brett Spencer 
men arrived at Gorgas Library on the day of the carnival, they were directed to a receiving table and given a general brochure about the libraries as well as a program listing the carnival events.

The general brochure, designed by Celeste Davis-Dill, was packed with lots of graphics and funny tips about the libraries, such as "Kick back and read on one of sofas or armchairs. Just be sure that you don't fall asleep and miss class!" The carnival program listed several activities that restarted every 15 minutes, sort of like rides at a real carnival or rolling events at a museum. Freshmen could come and go as they pleased. The activities included the following:

- Information fair. We asked several departments to help create colorful booths in an information fair on the second floor. Since the WOW event was held at the Gorgas Library, we asked our colleagues at the specialized libraries to come over and create booths in Gorgas showcasing the most useful (and entertaining) resources in their libraries for freshmen students.

We also suggested that they feature lots of attention-getters and interactivity. Responding in true carnival style, the specialized libraries ran virtual tours, gave out gobs of candy, created word puzzles of library terms, displayed archival manuscripts about university sports history, and even sold students on their libraries by passing out brochures listing the restaurants conveniently located next to their facilities. The Gorgas Library's Government Documents, Music, and Circulation departments also created booths with intriguing items from their collections, such as CIA materials from Government Documents.

In designing the title banner for their booths, many organizers used trifold background panels with library photos, while other organizers asked artistic staff to draw signs on white backboards with magic markers. Exuding the gusto of ride promoters at a carnival, the friendly librarians, staff, and student workers started up conversations with passing students about library resources and services.

- Roller coaster tours. Having browsed through the Information Fair, many of the students "boarded" the roller coaster tour on Gorgas Library's second floor, accompanied by a tour guide who led them up and down library stairs and elevators. From the initial plunge to the library basement to the final ascent to the fourth floor stacks, students learned about library resources and services while becoming familiar with its physical layout. Many students, unfamiliar with the older format, considered the microforms a carnival oddity, although one correctly identified the collection as an excellent tool for primary source research, saying, "It's what people in movies use to investigate the bad guys." Coaster riders were also impressed with the

\section{Six tips for a successful carnival}

Finding a fun theme for outreach events, like a carnival, can introduce many students to library services.

While most libraries may not have quite the glitz and glamour of a three-ring circus, we do offer invaluable services that many students will want to learn about, especially if we market to them in an appealing way.

Here are a few tips if you decide to offer a carnival at your library:

- Designate some staff to serve as "show people" who float around the carnival area and guide students from one activity to another.

- Post lots of signage to help guide the large crowds.

- Inform carnival staff of all the events and their locations.

- Be adaptable; flexibility and creativity are key.

- Collaborate with other campus organizations to maximize opportunities for student outreach.

- Keep statistics, take lots of photos, and have fun. 
SMART Boards available for their use in the library's group study rooms.

- Library cinema. After the wild ride of the library roller coaster tour, it was time for the students to sit and be bewitched by a brief video about research habits. The humorous video depicted a student working on a research paper with an angel and demon on opposite shoulders giving competing advice. The students were shown that although a smorgasbord of information can be found on Google or Wikipedia, the library resources are where true information connoisseurs perform feats of search. With the video's director Josh Sahib on hand to answer questions, an enchanting discussion followed about how these new students could avoid the perilous pitfalls of plagiarism. Sahib also took the opportunity to promote the Gorgas Library's Sanford Media Center, a leadingedge facility for digital media production, by explaining how he had used its technology to create the movie.

\section{- Library survivor} show. Reference librarian Barbara Dahlbach dazzled audiences with 11 back-to-back instruction sessions in our electronic classroom. Showing the skill and energy of a trapeze artist translated into a library setting, she demonstrated searching tricks in the Libraries' Catalog and Academic Search

Premier. The class sizes ranged from one to a dozen or more. After the show, students raved to other library staff about the marvelous information they received in Dahlbach's class. Tip sheets were also offered to students as souvenirs.

- Grab bag. Members of the circulation staff worked a grab bag table. Students first drew a slip from one bag. Each of the slips had a "Fun Fact" about the libraries. For example, one slip promoting our coffee shop as a group study area went like this: "Gorgas Library is caffeinated! Java City located on the first floor, offers hot and cold beverages to suit your tastes. The Café is a great place to study with friends."

After reading their Fun Fact, the students could draw from another bag depending on the color of their slip. Students with purple slips grabbed promotional jump drives from the purple bag, for example. Blue, red, and white slips could draw from other bags filled with ALA "Read" celebrity bookmarks, alligator clips, lanyards, candy bars, or other prizes.

\section{Conclusion}

More than 150 freshmen (and other) students flocked to the UA Libraries' carnival. The students were very conscientious learners who absorbed information with the same excitement of true carnival participants. We found that the carnival plan worked better than the open house format used last year; offering a carnival of events helped us accommodate a large gathering of students, while providing more opportunities for specialized instruction and personal contact through the small group "rides" and "sideshows."

Although we had no sword swallowers or lion-and-tiger shows, we did supply students with a lot of information and suggest ways that they could get the most from their campus libraries.

\section{Note}

1. www.youtube.com/watch?v =zYQ3XT4GBqY. $\boldsymbol{n}$ 